\title{
High Antioxidant Activity and Low Toxicity of Gold Nanoparticles Synthesized With Virola Oleífera: An Approach Using Design of Experiments
}

\section{Luis Contreras}

Universidade Federal do Espírito Santo

Debora Ferreira

Universidade Federal do Espírito Santo

Wanderson Keijok

Universidade Federal do Espírito Santo

Laryssa Silva

Universidade Federal do Espírito Santo

André da Silva

Instituto Federal do Espírito Santo

Eloi da Silva Filho

Universidade Federal do Espírito Santo

Jairo Oliveira

Universidade Federal do Espírito Santo

Marco Guimaraes ( $\nabla$ marco.guimaraes@ufes.br)

Universidade Federal do Espírito Santo

\section{Research Article}

Keywords: Antioxidant activity, factorial design, gold nanoparticles, green synthesis, Virola oleifera

Posted Date: December 28th, 2020

DOI: https://doi.org/10.21203/rs.3.rs-133428/v1

License: (c) (1) This work is licensed under a Creative Commons Attribution 4.0 International License.

Read Full License 


\title{
High antioxidant activity and low toxicity of gold nanoparticles synthesized with
}

\section{Virola oleifera: an approach using design of experiments}

Luis Alberto Contreras ${ }^{1}$, Debora Machado Ferreira ${ }^{1}$, Wanderson Juvencio Keijok ${ }^{1}$, Laryssa Pinheiro Costa Silva ${ }^{1}$, André Romero da Silva², Eloi Alves da Silva Filho ${ }^{3}$, Jairo Pinto de Oliveira ${ }^{1}$ and Marco Cesar Cunegundes Guimarães ${ }^{1 *}$

\footnotetext{
${ }^{1}$ Federal University of Espirito Santo, Av Marechal Campos1468, Vitória, ES 29.040-090, Brazil.

${ }^{2}$ Federal Institute of Espírito Santo, Av. Morobá, 248 - Morobá, Aracruz, ES, 29192-733, Brazil.

${ }^{3}$ Department of Chemistry, Federal University of Espírito Santo (UFES), Vitoria, Brazil.

*Corresponding author: Marco Cesar Cunegundes Guimarães (marco.guimaraes@ufes.br).
}

\begin{abstract}
Metallic nanoparticles synthesized by plant extracts and biomolecules represent one of the most promising frontiers in the antioxidants field. Plant compounds apart from act as reducing agents, also allow functionalizing these nanoparticles having multiple applications in different industries. However, the low reproducibility and the difficulty in size, shape and stability control have made it difficult to produce on a large scale. Here we report an optimization process to obtain gold nanoparticles (AuNPs) from green synthesis using a factorial design aiming to present a controlled synthesis using Virola oleifera as a reductant agent. We evaluate the influence of the reaction time, temperature, stirring rate, $\mathrm{pH}$ and extract concentration monitoring the Localized surface-plasmon resonance (LSPR) band shift $(\Delta \lambda)$. The nanoparticles were characterized using Zeta potential, UV-vis, DLS, TEM, Raman spectroscopy, FTIR and XRD. The assynthesized AuNPs were stable and homogenous, octahedral, monodisperse, and in shape and size and showed great antioxidant activity determined with ABTS+ and DPPH. Furthermore, these nanoparticles presented low cytotoxicity. Finally, using the factorial design, we were able to develop an optimal path for green gold nanoparticles with high antioxidant activity, low toxicity and good morphological characteristic.
\end{abstract}

Keywords: Antioxidant activity; factorial design; gold nanoparticles; green synthesis; Virola oleifera. 


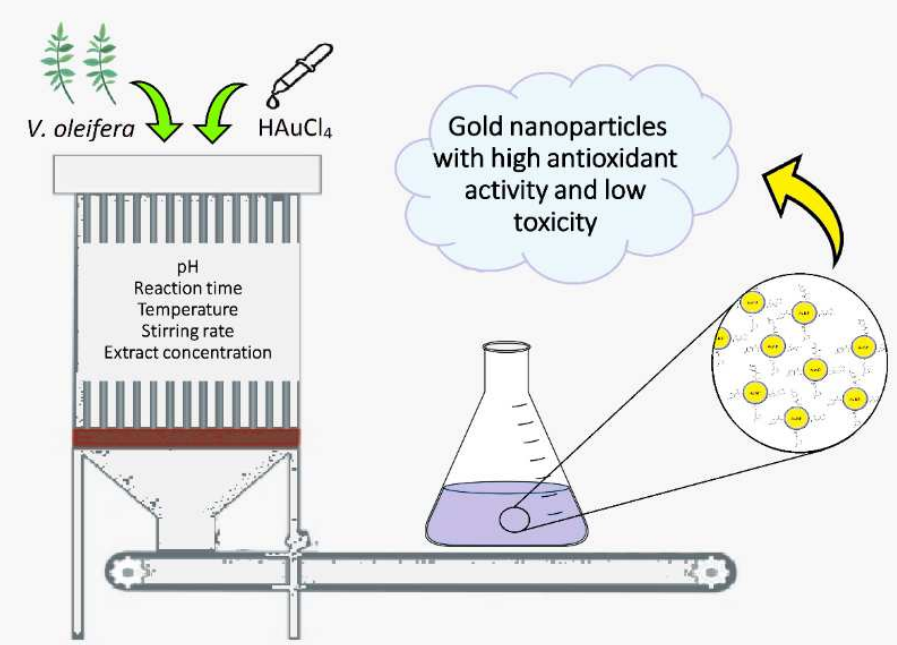

\section{INTRODUCTION}

Gold nanoparticle (AuNPs) are the most extensively studied NPs among all metals because of their multitude of applications, such as drug delivery, chemical and biological imaging, catalysis, therapeutic and diagnostics [1-5].

AuNPs are typically synthesized via physical and chemical, which are usually costly and environmentally hazardous. Therefore, the green biosynthesis has attracted increasing attention, increasing the interest eco-friendly synthesis and sustainability.

The trend in recent years has focused on the methods under the concept of "Green Chemistry", aiming the utilization of nontoxic capping agents, less hazardous reducing agents, and selection of environmentally benign solvents [6-9]. However, these methods are subject to many fluctuating aspects such as operational conditions (temperature, time, concentration, $\mathrm{pH}$, stirring rate, among others) and the wide variety of organic compounds present in plant extracts, causing some drawbacks, such as polydispersity, poor stability and even weak biocompatibility [10]. Thereby, the standardization that allows a monodisperse, stable, non-toxic and bioactive nanoparticles synthesis remain a challenge.

The traditional technique of 'one-factor-at-a-time' to optimize the factors that influence nanoparticles growth requires a lot of work and time without an accurate mathematical model equation to describe the whole process. Therefore, the aim of this work was to 
standardize AuNPs biosynthesis using a complex resin with a plethora of biomolecules, Virola oleifera, evaluating the reaction time, temperature, stirring rate, $\mathrm{pH}$ and extract concentration on the size and shape of nanoparticles using complete factorial design $3^{2}$. Then, some physico-chemical parameters were characterized and finally, the AuNPs showed good antioxidant activity in radical scavenging ABTS and DPPH analysis, low toxicity and good stability.

In summary, data presented here demonstrated that as synthesized AuNPs based on green synthesis needs to be controlled and optimized to AuNPs present and preserve its biological activity. This study might provide a good candidate and offer new insights for future translational study on AuNPs applications.

\section{MATERIAL AND METHODS}

\section{Plant material}

V. oleifera power was obtained according to Pereira et al (2015) [11]. The resin was obtained by making cuts in the bark of the $V$. oleifera tree and collected in an amber glass container, keeping it in the dark and at $4^{\circ} \mathrm{C}$ during the transportation to the laboratory. The resin was dried at $50^{\circ} \mathrm{C}$ and then ground to obtain $10 \mathrm{~g}$ of dry resin.

\section{Synthesis of gold nanoparticles}

The resin of the plant was added to a gold precursor solution in a ratio of three to one $(\mathrm{m} / \mathrm{m})$. The gold precursor was tetrachloroauric acid (Sigma-Aldrich, St. Louis, MO, USA) in a concentration of $2.5 \times 10^{-4} \mathrm{mmol} / \mathrm{L}$. For the synthesis, a factorial design 32 was carried out with 3 levels and 2 variables. The synthesis was performed according to the experimental design.

\section{Experimental design and statistical analysis}

The choice of variables and each of their levels was previously determined. Details on these experiments can be found in the Supporting Information (Table S1). Then, as the next step, a fractional factorial design $2^{(5-1)}$, with 2 levels and 5 variables, was assembled to know which is the main variable that influences the nanoparticle synthesis process (Table 1). The reaction time, temperature, stirring rate, $\mathrm{pH}$ and extract concentration 
were also evaluated in this step. In the final step, a $3^{2}$ factorial design was made with 3 levels and 2 variables to determine the optimum conditions for the nanoparticle synthesis (Table 2). For this step, the $\mathrm{pH}$ and reaction time were evaluated as independent variable.

Table 1. Fractional Design Matrix $2^{5-1}$ of Gold Nanoparticles Synthesized with V. oleifera extract.

\begin{tabular}{ccc}
\hline Variables & \multicolumn{2}{c}{ Study levels } \\
\hline & Low $(-)$ & High $(+)$ \\
\hline Time $(\mathrm{min})$ & 1 & 20 \\
Temperature $\left({ }^{\circ} \mathrm{C}\right)$ & 25 & 80 \\
$\mathrm{pH}$ & 4.7 & 8 \\
Concentration $(\mathrm{mg} / \mathrm{mL})$ & 5 & 10 \\
Agitation $(\mathrm{rpm})$ & 50 & 200 \\
\hline
\end{tabular}

Table 2. Complete Design Matrix $3^{2}$ of Gold Nanoparticles Synthesized with V. oleifera extract.

\begin{tabular}{cccc}
\hline \multirow{2}{*}{ Variables } & \multicolumn{3}{c}{ Study levels } \\
\cline { 2 - 4 } & Low $(-)$ & Center $(0)$ & High $(+)$ \\
\hline $\mathrm{pH}$ & 4.7 & 7.7 & 10.7 \\
Time $(\min )$ & 1 & 6 & 11 \\
\hline
\end{tabular}

The effects of each selected variable were analyzed using STATISTICA version 10.0. An analysis of variance (ANOVA) of the data was also performed, and the values were considered significant at values of $p<0.05$. The pareto diagram that identifying the significant variables are show in supplementary material (S1). The optimal values of the independent variables were determined using a three-dimensional analysis of the response surface of the independent and dependent variables.

\section{Gold nanoparticle characterization. (UV-Vis, TEM, DLS, FTIR, RAMAN and X-rays)}

The optical properties of the solutions were analyzed using the UV-vis absorption spectrophotometer (UV-1800 Shimadzu, Japan). Image J software was used to analyze the mean diameter and aspect ratio of 1000 particles from transmission electron microscopy images ((TEM-JEM-1400, JEOL, USA Inc. operated at 120kv). Diffraction Xray analysis was performed using the Phillips PW 1710 diffractometer (Cuk radiation) to evaluate the crystallographic structure of nanoparticles. For the analysis of stability and hydrodynamic size, the Microtac Zetatrac particle analyzer was used. Infrared spectrometry and Raman scattering were performed in the FTIR (FT- MIR FTLA 2000 
Bomem) and Raman (ALPHA $300 \mathrm{R}$ Confocal Raman Spectrometer). The total concentration of AuNPs was determined using ICP-MS (Perkin Elmer, Optima 7000, USA). The flocculation parameter were used for the stability analysis of the synthesized nanoparticles according to the Weisbecker [12] description, later modified by Mayya [13], taking and analyzing specific UV-vis measurements.

\section{RESULTS AND DISCUSSION}

\section{Statistical and full factorial design analysis}

The applied experimental design allowed the identification of the experimental factors fluencing the physicochemical properties of the AuNPs that directly affect size and consequently their monodispersion.

Previous fractional factorial design $\left(2^{5-1}\right)$ (Supplementary material) studies was applied to determined the variables that most influenced monodispersion of as synthesized AuNPs. Delta lambda $(\Delta \lambda)$ was the factor with the most significant variables, $\mathrm{pH}$ and time.

A full factorial design $\left(3^{2}\right)$ was conducted considering $\mathrm{pH}(4.7,7.7$ and 10.7$)$ and time (1, 6 and $11 \mathrm{~min}$ ) with three central points, the extract concentration were maintained at $250 \mathrm{rpm}, 25^{\circ} \mathrm{C}$ and $5 \mathrm{mg} \cdot \mathrm{mL}^{-1}$ respectively.

UV-vis absorption spectra show three regions well defined were according to the $\mathrm{pH}$ ranges (Fig. 1). When $\mathrm{pH}$ changes from acid to basic, $\Delta \lambda$ decrease. The $\mathrm{pH}$ variation influences directly the $\Delta \lambda$, and consequently the size variation of AuNPs. The presence of deprotonated (at basic $\mathrm{pH}$ ) and protonated (at acid $\mathrm{pH}$ ) form of carboxylic acid in the $V$. oleifera extract can be relationed with this phenomenum. When $\mathrm{COO}^{-}$group interact with gold atoms in a basic $\mathrm{pH}$ there has a decrease in the size of AuNPs. On the other hand the interaction between $\mathrm{COOH}$ results on increase AuNPs size [14].

To investigate influence of the time on $\Delta \lambda$ variation, we vary the time on three levels (1, 6 and $11 \mathrm{~min}$ ) within each $\mathrm{pH}$ range $(4.7,7.7$ and 10.7) (Table 3). No significant variation was identified that would interfere in the $\Delta \lambda$.

Through ANOVA analysis the $\mathrm{pH}$ was the most influential variable (Table 4). It should be highlighted that complete factorial design showed that none combinatorial effects was significant for $\Delta \lambda$. 


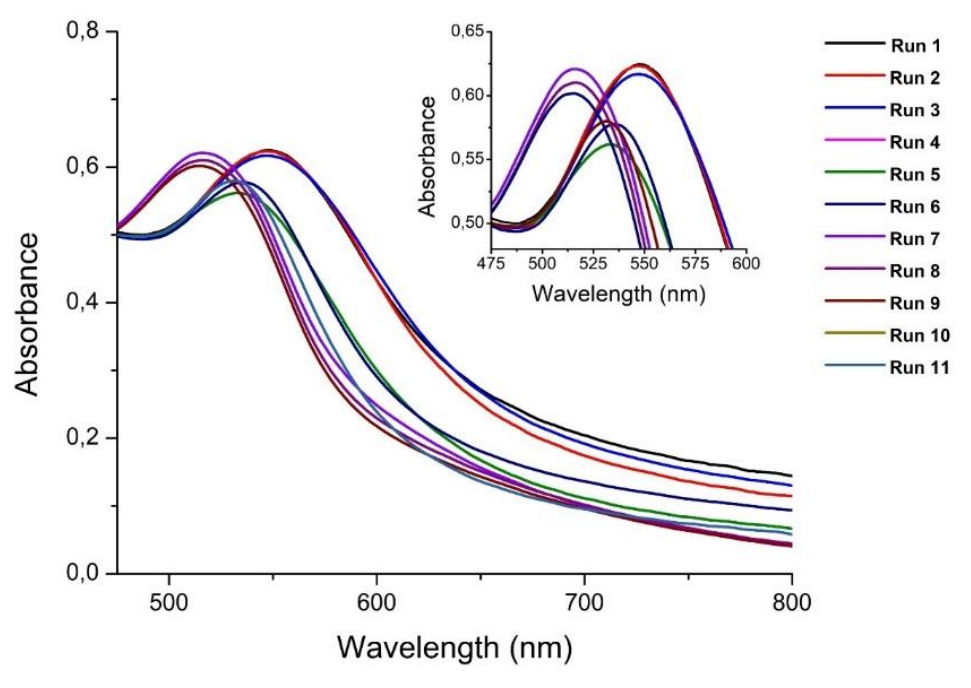

Figure 1. UV-Vis absorption of 11 samples synthesized according to full factorial design $3^{2}$. Run 1 ( $\mathrm{pH} 4.7$, Time 1 min); Run 2 ( $\mathrm{pH}$ 4.7, Time 6 min); Run 3 (pH 4.7, Time 11 min); Run 4 (pH 7.7, Time 1 min); Run 5 (pH 7.7, Time 6 min); Run 6 (pH 7.7, Time 11 min); Run 7 (pH 10.7, Time 1 min); Run 8 (pH 10.7, Time 6 min); Run 9 (pH 10.7, Time $11 \mathrm{~min})$; Run 10 (pH 7.7, Time 6 min); Run 11 (pH 7.7, Time 6 min).

Table 3. Complete factorial design matrix $3^{2}$ of gold nanoparticle synthesis with $V$. oleifera extract using $\Delta \lambda$ as the response variable.

\begin{tabular}{cccc}
\hline Run & \multicolumn{2}{c}{ Variables } & \multicolumn{2}{c}{ Response } \\
\hline $\mathbf{1}$ & $\mathrm{pH}$ & Time $(\mathrm{min})$ & $\Delta \lambda$ \\
$\mathbf{2}$ & $4.7(-)$ & $1(-)$ & 36 \\
$\mathbf{3}$ & $4.7(-)$ & $6(0)$ & 33 \\
$\mathbf{4}$ & $4.7(-)$ & $11(+)$ & 32 \\
$\mathbf{5}$ & $7.7(0)$ & $1(-)$ & 22 \\
$\mathbf{6}$ & $7.7(0)$ & $6(0)$ & 19 \\
$\mathbf{7}$ & $7.7(0)$ & $11(+)$ & 24 \\
$\mathbf{8}$ & $10.7(+)$ & $1(-)$ & 3 \\
$\mathbf{9}$ & $10.7(+)$ & $6(0)$ & 1 \\
$\mathbf{1 0}$ & $10.7(+)$ & $11(+)$ & 0 \\
$\mathbf{1 1}$ & $7.7(0)$ & $6(0)$ & 19 \\
\end{tabular}

Table 4. ANOVA of nanoparticles synthesis using complete planning matrix $3^{2}$ of AuNPs.

\begin{tabular}{cccccc}
\hline Variables & SS* & Df* & MS* & $\mathbf{F}^{*}$ & $\mathbf{p}^{*}$ \\
\hline $\mathbf{( 1 )} \mathbf{p H}(\mathbf{L})$ & $\mathbf{1 5 6 8 . 1 6 7}$ & $\mathbf{1}$ & $\mathbf{1 5 6 8 . 1 6 7}$ & $\mathbf{4 6 5 . 6 7 0 7}$ & $\mathbf{0 . 0 0 0 0 0 4}$ \\
$\mathbf{p H}(\mathbf{Q})$ & $\mathbf{3 4 . 8 7 9}$ & $\mathbf{1}$ & $\mathbf{3 4 . 8 7 9}$ & $\mathbf{1 0 . 3 5 7 4}$ & $\mathbf{0 . 0 2 3 5 1 0}$ \\
(2) Time $(\min )(\mathrm{L})$ & 4.167 & 1 & 4.167 & 1.2373 & 0.316593 \\
Time $(\min )(\mathrm{Q})$ & 13.279 & 1 & 13.279 & 3.9432 & 0.103812 \\
1L by 2L & 0.250 & 1 & 0.250 & 0.0742 & 0.796157 \\
Error & 16.838 & 5 & 3.368 & & \\
Total SS & 1628.909 & 10 & & & \\
\hline
\end{tabular}


*SQ - Sum of Squares; DF - Degrees of Freedom; MS - Mean Square; F - test statistic; P - p value; L - linear; Q - Quadratic. The significant variables are shown in bold.

The Response Surface Graph (Fig. 2) was applied to determine the best region where the optimal response occurs. The reduction, nucleation, growth and stabilization of nanoparticles occurs very fast.
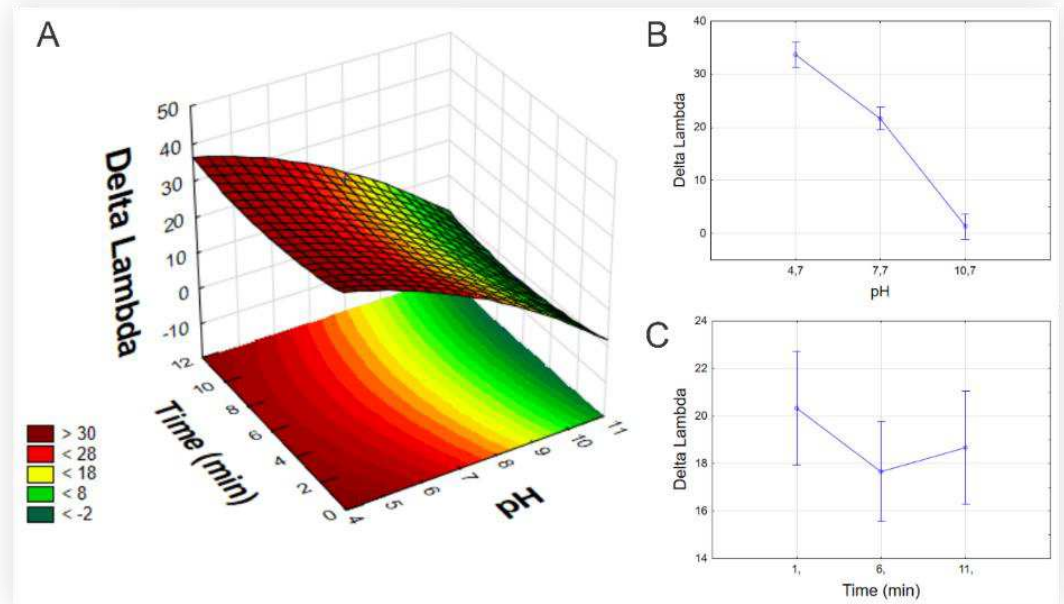

Figure 2. (A) Response surface graph by complete factorial design $3^{2}$ of gold nanoparticles synthesis with $V$. oleifera extract. (B) Influence of $\mathrm{pH}$ on $\Delta \lambda$ response variable. (C) Influence of Time in relation to the response variable $\Delta \lambda$.

\section{Characterization of Gold Nanoparticles}

At the end of full factorial design, three assays were determined: AuNPs synthesized at values of $\mathrm{pH} 4.7,7.7$ and 10.7, which can be interpreted as groups of AuNPs of different sizes $35 \mathrm{~nm}, 22 \mathrm{~nm}$ and $9 \mathrm{~nm}$ respectively (Fig. $3 \mathrm{~A}$ and Fig. 3G).

X-ray diffraction showed a crystal structure of AuNPs (Fig. 3B), in which four diffraction peaks are observed at $2 \theta=38.2^{\circ}, 43.5^{\circ}, 65^{\circ}$ and $77.7^{\circ}$ indexed as (111), (200), (220) and (311) for crystalline metallic gold refractions with a face centered cubic crystal structure (fcc) [15-17].

TEM images mainly showed spherical and non-agglomerated AuNPs obtained from the three conditions with different $\mathrm{pH}(4.4,7.7$ and 10.7) (Fig. 3C, Fig. 3D y Fig. 3E). The presence of a cloud around the nanoparticles confirmed the existence of organic compounds formed by molecules that come from the plant extract. 
The AuNPs - pH 4.7 showed an aspect ratio of 0.905892, presenting a higher sphericity, and the AuNPs - pH 7.7 and AuNPs - pH 10.7, presented values of 0.844786 and 0.710228 respectively, showing a lower sphericity $[18,19]$ (Fig. 3F).

The surface potential in all groups of AuNPs was also measured using the zeta potential. AuNPs - pH 4.7 and AuNPs - pH 7.7 show moderate stability with a positive charge of 21.59 and $20.37 \mathrm{mV}$ respectively, finally the zeta potential for AuNPs - pH 10.7 was 4.27 $\mathrm{mV}$ showing rapid aggregation [20-23] (Fig. 4A). It can be inferred that the molecules present on the surface of the AuNPs are mainly composed of positively charged groups that are responsible for the good stability of the nanoparticles. This can be attributed to the presence of polyphenols, flavonoids and proteins from the plant extract $[24,25]$.

The hydrodynamic size of the AuNPs was measured by DLS to determine the size of the AuNPs coated with all the phytochemicals present in V. oleifera. AuNPs - pH 4.7 and AuNPs - pH 7.7 had hydrodynamic sizes close to 100nm, while AuNPs - pH10.7 had hydrodynamic sizes close to $1000 \mathrm{~nm}$ (Fig. 4B, Fig. 4C and Fig. 4D). When comparing these sizes with those obtained by TEM they are $35 \mathrm{~nm}, 24 \mathrm{~nm}$ and $8 \mathrm{~nm}$ respectively (Fig. 3G) the difference in values observed for the same nanomaterials is evident as a consequence of the cloud formed by molecules that come from the plant extract, since the connection of these molecules with the surface of the nanomaterial results in a larger hydrodynamic diameter. 

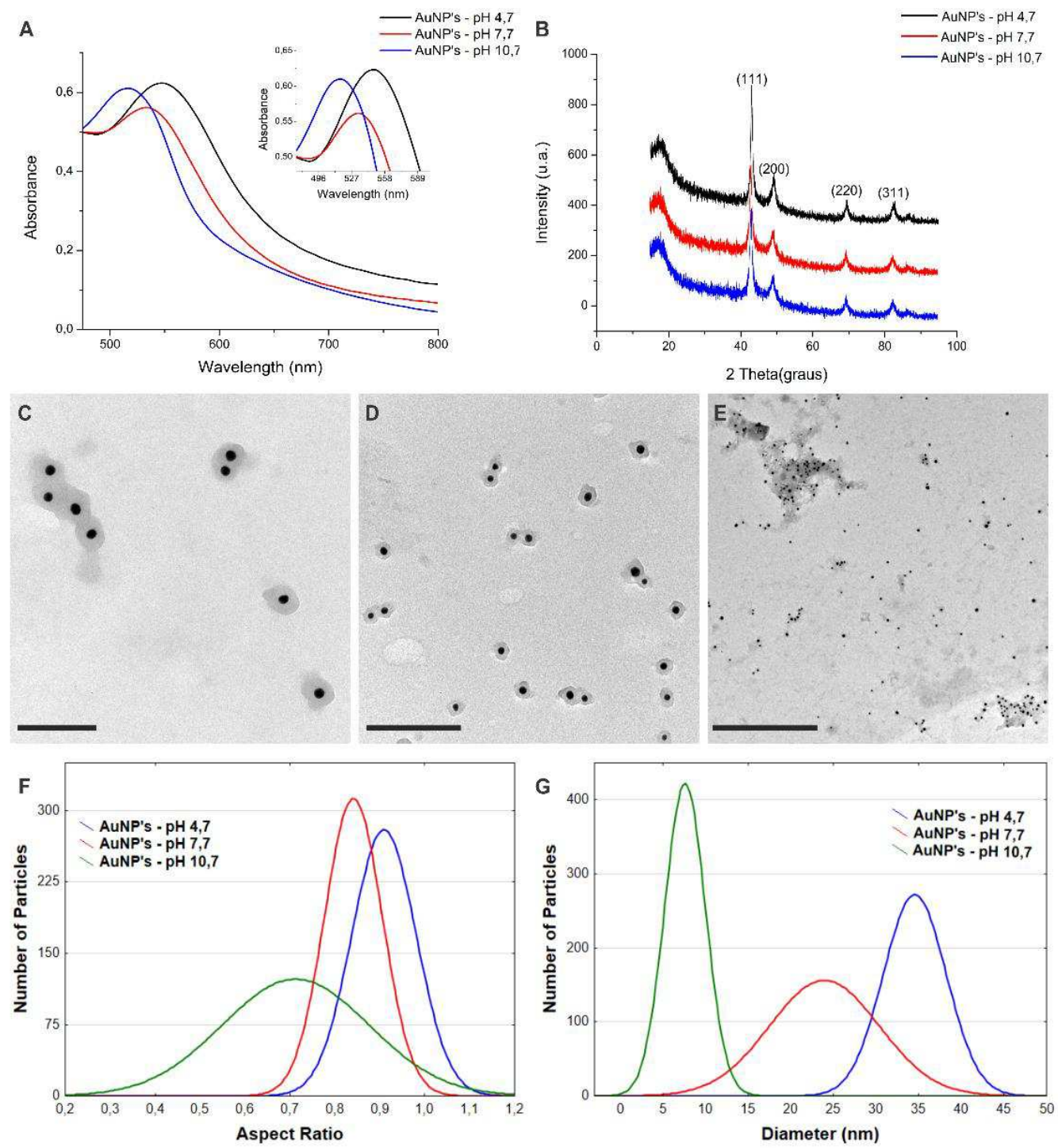

Figure 3. (A) SPR band of AuNPs synthesized using $V$. oleifera extract as reducing agent with different pHs. (B) X-ray diffraction of AuNPs. Images obtained by transmission electron microscopy (C) AuNPs pH - 4.7, (D) AuNPs - pH 7.7, and (E) AuNPs - pH 10.7, scale bar $200 \mathrm{~nm}$. (F) Aspect ratio of 1000 particles obtained from images acquired by transmission electron microscopy (TEM) and (G) Histogram showing the Gaussian distribution of diameter. 

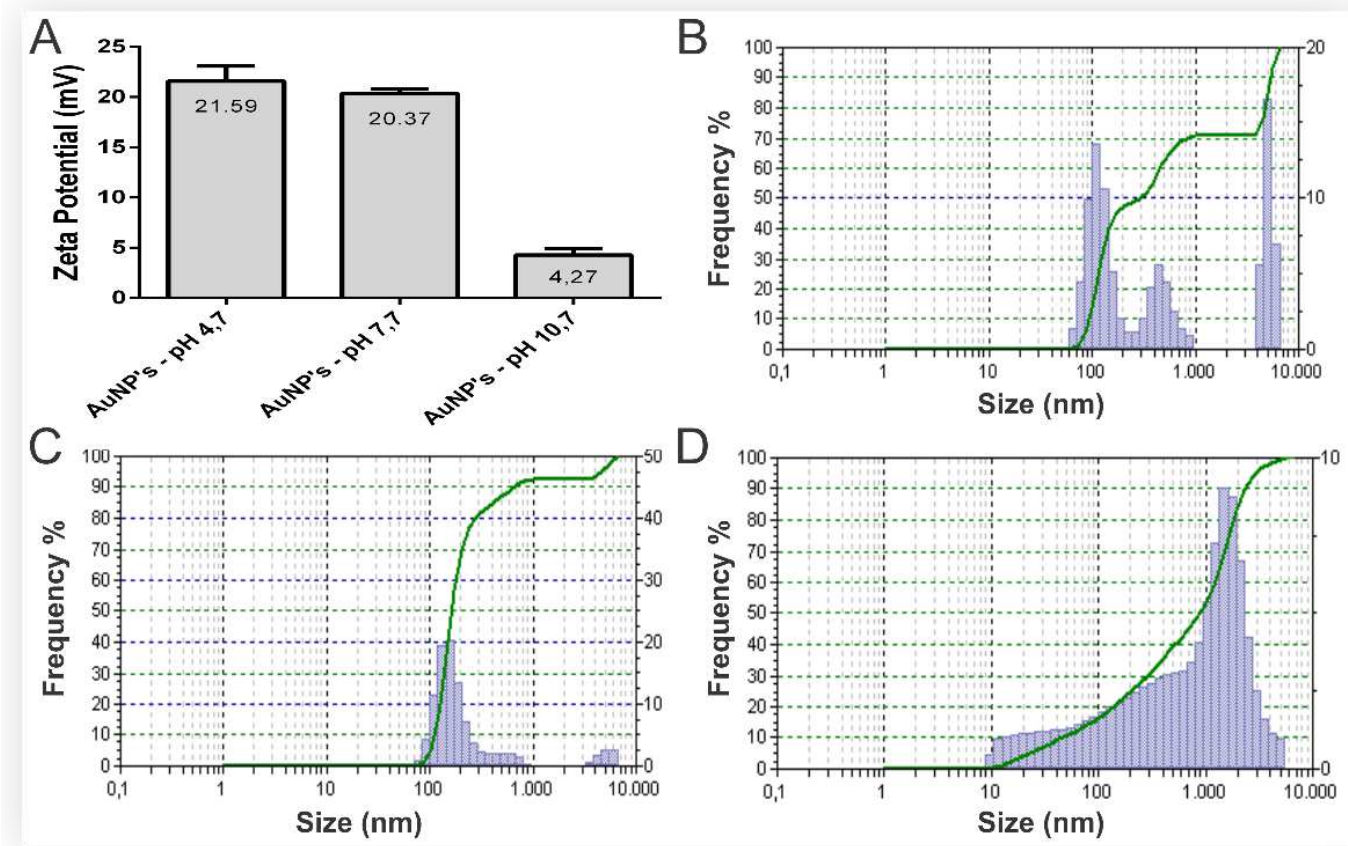

Figure 4. (A) Zeta potential of synthesized nanoparticles. (B) Nanoparticle DLS graph of AuNPs - pH 4. 7. (C) Nanoparticle DLS graph of AuNPs - pH 7.7. (D) Nanoparticle DLS graph of AuNPs - pH 10.7.

\section{Determination of the concentration of AuNPs in the colloidal solution.}

The concentration of AuNPs in a colloidal solution can be calculated knowing the weight of gold (W. Au) used for the synthesis of nanoparticles (only $\mathrm{Au}$ ) and the density of gold ( $)$. First, the reduced volume of gold (V. Au) is calculated using Eq1: V. Au =W. Au / $\rho$. Secondly, knowing the average size of the nanoparticles using TEM, the volume of a single nanoparticle (V. AuNPs) is calculated using Eq2: V. AuNPs $=\left(4 * p^{*} r^{3}\right) / 3$ (provided that the nanoparticle is spherical). Thirdly, the number of particles in the colloidal solution (N. SC) is calculated using Eq3: N. SC = V. Au / V. AuNPs. Finally, the colloidal concentration of the nanoparticles (C. AuNPs) is calculated with the Eq4: $\mathrm{C}$. AuNPs $=\mathrm{N}$. SC / Final volume of colloidal solution [26-28]. Table 5 shows the concentration of AuNPs obtained for each run, observing a high concentration of nanoparticles in the prepared colloids.

Table 5. Determination of the concentration of AuNPs in the colloidal solution.

\begin{tabular}{cccc}
\hline Nanoparticles & $\begin{array}{c}\text { Average } \\
\text { diameter } \\
(\mathbf{n m})\end{array}$ & $\begin{array}{c}\text { Average } \\
\text { radius } \\
(\mathbf{n m})\end{array}$ & $\begin{array}{c}\text { Colloidal Concentration } \\
\text { (NP / ml) }\end{array}$ \\
\hline AuNPs - pH 4.7 & 35 & 17.5 & $1.14 \mathrm{E}+11$ \\
AuNPs - pH 7.7 & 22 & 11 & $4.58 \mathrm{E}+11$ \\
AuNPs - pH 10.7 & 9 & 4.5 & $6.68 \mathrm{E}+12$ \\
\hline
\end{tabular}




\section{Surface Analysis}

In order to identify the functional groups of the formed AuNPs, Fourier transform infrared spectroscopy (FT-IR) and RAMAN spectroscopy were used. FT-IR bands revealed for both extract and as synthesized AuNPs are found to be located as following, 1601 $\mathrm{cm}-1$ which is attributed to the $C=O$ stretch of the carbonyl group (Fig. $5 \mathrm{~A}$ ), at $1433 \mathrm{~cm}$ 1 attributable to axial deformation of $\mathrm{CH}$ aliphatic groups ; at $1510 \mathrm{~cm}-1$ and $1513 \mathrm{~cm}-1$ due to the presence of aromatic structures $C=C$, at $1280 \mathrm{~cm}-1$ it is related to the vibratory stretch C-O of the alcohol bonds, at $1090 \mathrm{~cm}-1$ it is related to the ester group, and finally at $1034 \mathrm{~cm}-1$ it is related to $\mathrm{C}-\mathrm{H}$ bending vibrations [29].

In the Raman spectrum, the following peaks were observed at $1347 \mathrm{~cm}-1$ and $1579 \mathrm{~cm}$ 1 both in the $V$. oleifera extract and in all AuNPs. These vibration peaks can be attributed to the symmetric and asymmetric stretching of the carboxylate group (COO-) respectively. The distance between the stretching modes also provides information. The distance of $220 \mathrm{~cm}-1$ indicates that the carboxyl groups are mono-dentate complexes with the metal [30] (Fig. 5B). The Raman spectrum showed high intensity for the AuNPs complex. The similarity between FTIR and Raman spectra indicates that polyphenols, hydroxyl groups, carboxylic acids of the biomolecules present in extract are potentially responsible for the reduction and stabilization of AuNPs. Besides that, changes in the bands of some functional groups indicate that flavonoids and terpenes are attached to the AuNPs [31].
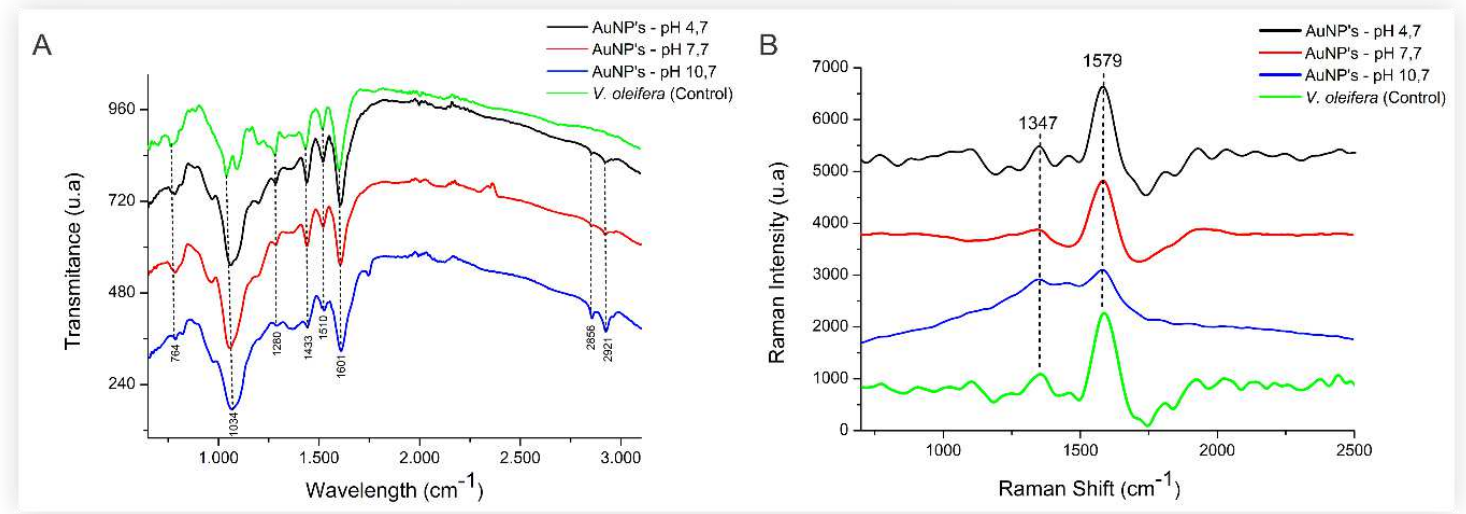

Figure 5. (A) Raman spectra and (B) Infrared spectrum of gold nanoparticles synthesized with $V$. oleifera with different $\mathrm{pHs}(4.7,7.7,10.7)$ and $V$. oleifera extract. 


\section{Stability of AuNPs}

Stability tests were performed only in the midpoint ( $\mathrm{pH}$ 7.7). The formulation prepared at $\mathrm{pH} 7.7$ proved to be stable between $\mathrm{pH} 7$ to 11 and presented a high degree of flocculation at an acidic $\mathrm{pH}$ and a very basic $\mathrm{pH}$ (Fig. 6A and Fig. 6B). The sample prepared at $\mathrm{pH} 7.7$ shows to be stable at a salt concentration of less than $10 \mathrm{mM} \mathrm{NaCl}$ (Fig. $6 \mathrm{C}$ and Fig. 6D).
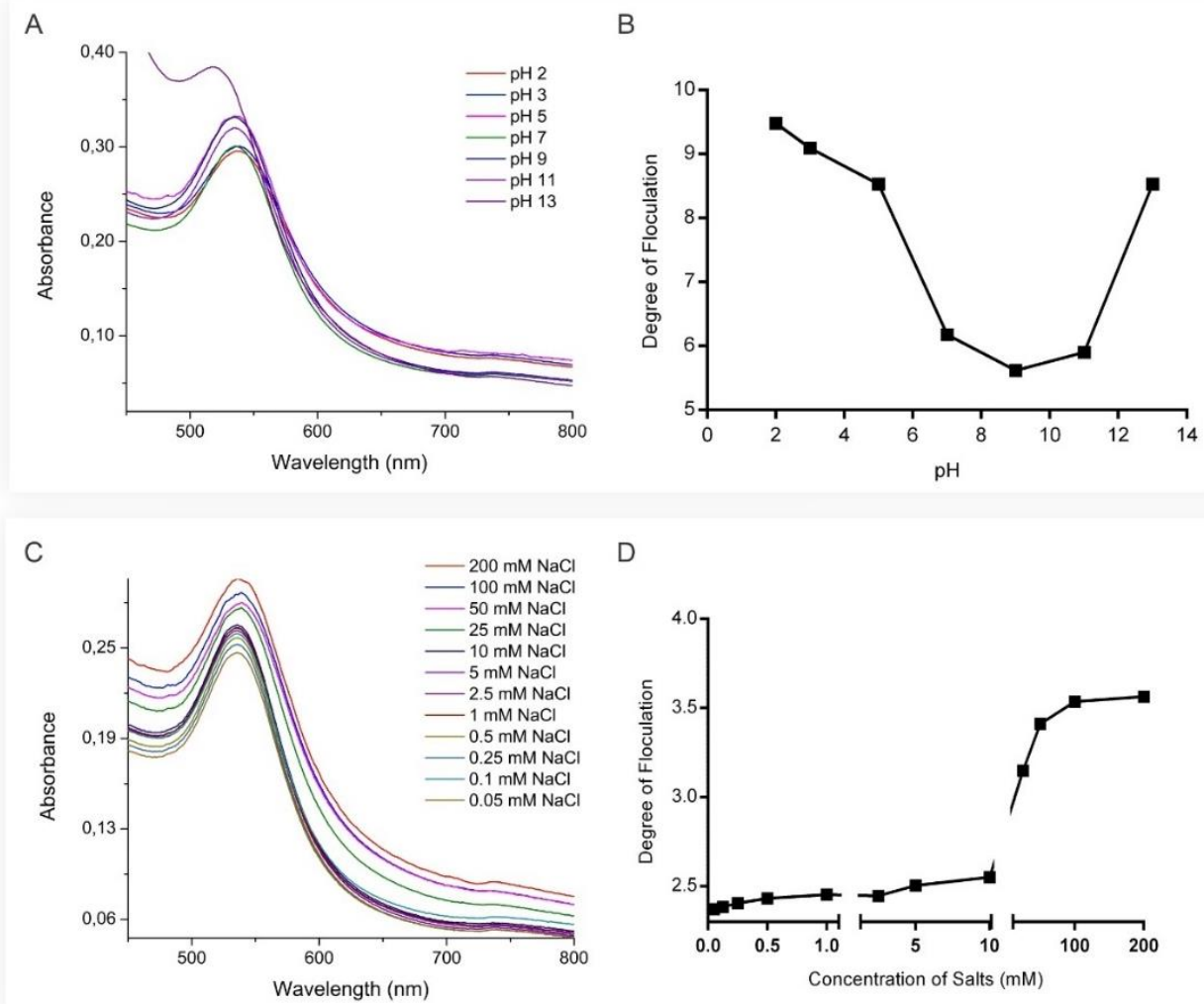

D

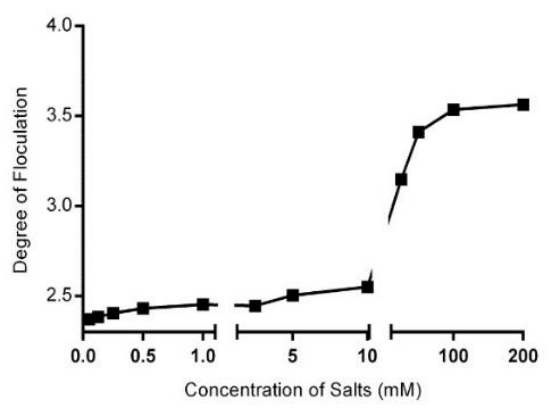

Figure 6. Absorption spectra showing the AuNPs prepared at $\mathrm{pH} 7.7$ in the presence of different salt concentrations (A) and $\mathrm{pH}(\mathrm{C})$. Flocculation degree based on the increase of the area between 600 and $800 \mathrm{~nm}$ in different salt concentrations (B) and pH (D).

\section{Antioxidant activity of AuNPs}

In this study, two antioxidant evaluation methods, ABTS + and DPPH, were used to investigate the antioxidant activity of AuNPs - pH7.7. The radical scavenging activity of AuNPs was estimated by comparing the percentage of ABTS + radical inhibition with Trolox and $V$. oleifera. The results revealed the existence of an effective radical scavenging activity in the AuNP solution compared to Trolox (Fig. 7A). The radical scavenging activity was $73.4 \%$, for AuNPs - $\mathrm{pH}$ 7.7. The $V$. oleifera extract showed a greater inhibitory activity with $71.6 \%$ greater than the Trolox which was $52.7 \%$. Similarly, 
the DPPH assay showed a similar pattern of reducing activity for AuNPs - $\mathrm{pH} 7.7, \mathrm{~V}$. oleifera and Trolox (Fig. 7B) being 69\%, 66.6\% and 53\% respectively. As can be seen, the antioxidant activity of the AuNPs was greater than the antioxidant activity of the $V$. oleifera extract, possibly due to modifications in the electrostatic density of the surface molecules [32, 33].
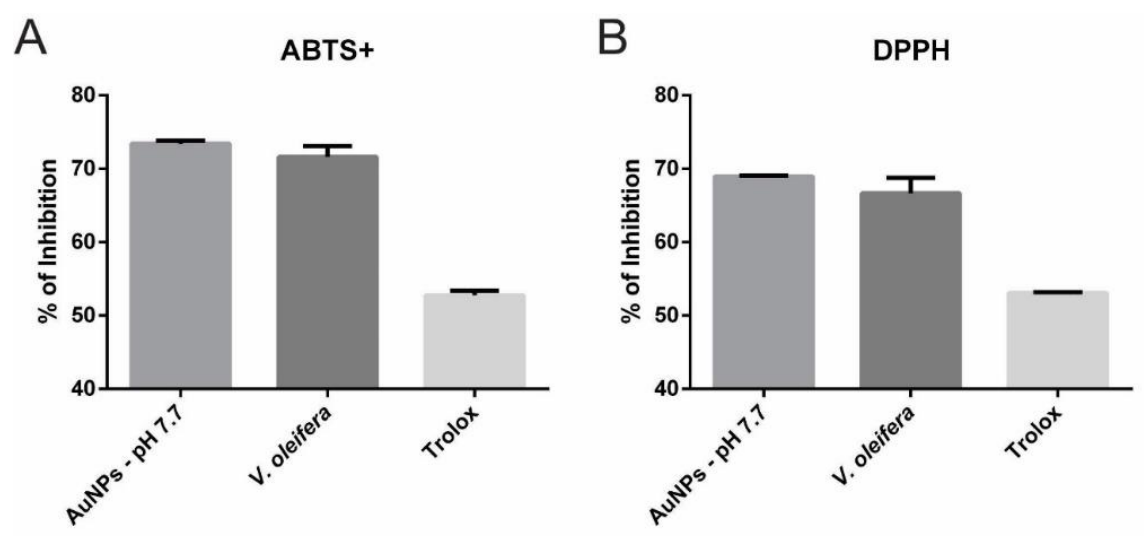

Figure 7. Comparison between the antioxidant activity of AuNPs - pH7.7, V. oleifera extract and Trolox (control) using (A) ABTS + and (B) DPPH assay.

\section{Cytotoxicity of the AuNPs}

An Alamar Blue assay was performed to assess the cytotoxicity of AuNPs by determining the survival percentage of the J774A.1 cell line (Fig. 8). The AuNPs presented low cytotoxicity at low concentrations, with an IC50 value of $130 \mathrm{ug} / \mathrm{ml}$. It has been reported that the cytotoxicity of the AuNPs depends on its size, shape, surface charge and the exposed cell line [34, 35], so that the smaller the nanoparticle size, the greater the distribution in the cell and the greater the toxicity, which could explain why the $V$. oleifera extract is more cytotoxic in the same concentrations as the AuNPs. The surface charge and the size of the AuNPs (around 100nm) would cause less affinity for the cell [36-38] and consequently higher survival percentage. 

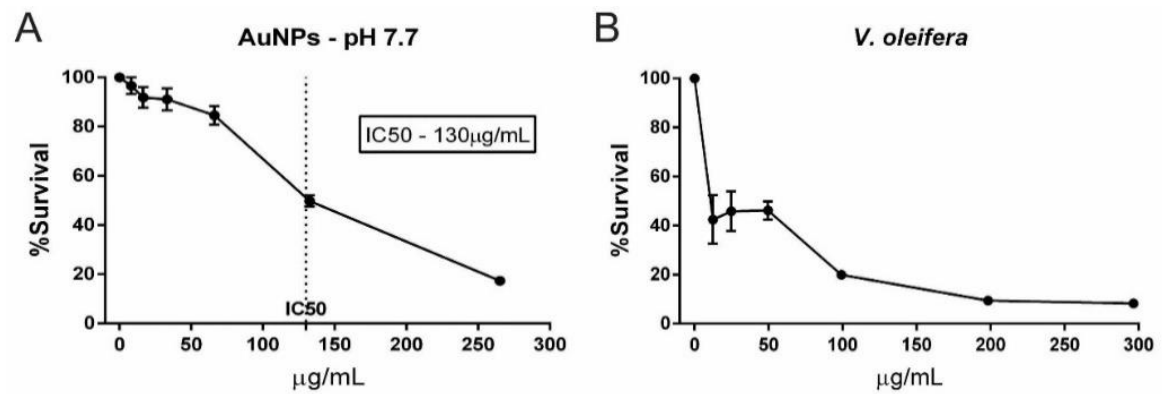

Figure 8. Survival percentage of (A) AuNPs at pH 7.7 and (B) V. oleifera extract.

\section{CONCLUSIONS}

We describe a controlled and reproducible process of green synthesis of gold nanoparticles, which was achieved through a fractional factorial design $\left(2^{5-1}\right)$ to evaluate the variables that interfere in the synthesis of gold nanoparticles using $V$. oleifera extract. Through the complete factorial design $\left(3^{2}\right)$ the synthesis process was optimized, identifying the reaction time and $\mathrm{pH}$ as the variables that most influenced during the synthesis to obtain nanoparticles of different sizes.

The synthesized nanomaterials were monodisperse, almost spherical and showed good stability, characteristics determined by UV-vis, TEM, DLS and Zeta Potential. Furthermore, the similarity of the spectra showed in FTIR and Raman between the $V$. oleifera extract and the AuNPs, indicates the adsorption of the extract on the surface of the AuNPs. An evaluation of the flocculation parameter was carried out, with the aim of applying these NPs in biological systems, showing that the NPs were stable in a pH range (7 to 11 ) and ionic strength (0.05 to $\left.10 \mathrm{mM}) . \mathrm{L}^{-1} \mathrm{NaCl}\right)$.

Finally, the AuNPs showed even greater antioxidant activity than the $V$. oleifera and trolox extract with low cytotoxicity at low concentrations. This study might provide a good candidate and offer new insights for use of green gold nanoparticles as antioxidant on the market. 


\section{REFERENCES}

1. Cheng, J., Wang, X., Nie, T., Yin, L., Wang, S., Zhao, Y. \& Mei, H. (2020). A novel electrochemical sensing platform for detection of dopamine based on gold nanobipyramid/multi-walled carbon nanotube hybrids. Analytical and Bioanalytical Chemistry, 1-9.

2. Jefremow, A., \& Neurath, M. F. (2020). Nanoparticles in Gastrooncology. Visceral Medicine, 36(2), 88-94.

3. Cole, L. E., McGinnity, T. L., Irimata, L. E., Vargo-Gogola, T., \& Roeder, R. K. (2018). Effects of bisphosphonate ligands and PEGylation on targeted delivery of gold nanoparticles for contrast-enhanced radiographic detection of breast microcalcifications. Acta biomaterialia, 82, 122-132.

4. Li, W., Cao, Z., Liu, R., Liu, L., Li, H., Li, X., ... \& Liu, Y. (2019). AuNPs as an important inorganic nanoparticle applied in drug carrier systems. Artificial cells, nanomedicine, and biotechnology, 47(1), 4222-4233.

5. P. G. Calavia, M. J. Marin, I. Chambrier, M. J. Cook, D. A. Russell, (2018). Towards optimisation of surface enhanced photodynamic therapy of breast cancer cells using gold nanoparticle-photosensitizer conjugates. Photochem. Photobiol. Sci. 17 (3): 259-366.

6. Sunayana, N., Uzma, M., Dhanwini, R. P., Govindappa, M., Prakash, H. S., \& Raghavendra, B. V. (2020). Green synthesis of gold nanoparticles from Vitex negundo leaf extract to inhibit lipopolysaccharide-induced inflammation through in vitro and in vivo. Journal of Cluster Science, 31(2), 463-477.

7. Gavamukulya, Y., Maina, E. N., Meroka, A. M., Madivoli, E. S., El-Shemy, H. A., Wamunyokoli, F., \& Magoma, G. (2020). Green synthesis and characterization of highly stable silver nanoparticles from ethanolic extracts of fruits of Annona muricata. Journal of Inorganic and Organometallic Polymers and Materials, 30(4), 1231-1242.

8. Islam, N. U., Jalil, K., Shahid, M., Rauf, A., Muhammad, N., Khan, A., ... \& Khan, M. A. (2019). Green synthesis and biological activities of gold nanoparticles functionalized with Salix alba. Arabian Journal of Chemistry, 12(8), 2914-2925.

9. Badeggi, U. M., Ismail, E., Adeloye, A. O., Botha, S., Badmus, J. A., Marnewick, J. L., ... \& Hussein, A. A. (2020). Green Synthesis of Gold Nanoparticles Capped with Procyanidins from Leucosidea sericea as Potential Antidiabetic and Antioxidant Agents. Biomolecules, 10(3), 452.

10. Makarov, V. V., Love, A. J., Sinitsyna, O. V., Makarova, S. S., Yaminsky, I. V., Taliansky, M. E., \& Kalinina, N. O. (2014). "Green" nanotechnologies: synthesis of metal nanoparticles using plants. Acta Naturae (англоязычная версия), 6(1 (20)).

11. Bôa, I. S. F., Porto, M. L., Pereira, A. C. H., Ramos, J. P. L., Scherer, R., Oliveira, J. P., ... \& Pereira, T. M. C. (2015). Resin from Virola oleifera protects against radiocontrast-induced nephropathy in mice. PloS one, 10(12). 
12. Weisbecker, C. S., Merritt, M. V., \& Whitesides, G. M. (1996). Molecular selfassembly of aliphatic thiols on gold colloids. Langmuir, 12(16), 3763-3772.

13. Mayya, K. S., Patil, V., \& Sastry, M. (1997). On the stability of carboxylic acid derivatized gold colloidal particles: the role of colloidal solution $\mathrm{pH}$ studied by optical absorption spectroscopy. Langmuir, 13(15), 3944-3947.

14. Yan, JK, Liu, JL, Sun, YJ, Tang, S., Mo, ZY y Liu, YS (2015). Síntesis verde de nanopartículas de oro cubiertas de curdlán carboxílico biocompatibles y su interacción con proteínas. Polímeros de carbohidratos, 117, 771-777.

15. Irfan, M., Ahmad, T., Moniruzzaman, M., Bhattacharjee, S., \& Abdullah, B. (2020). Size and stability modulation of ionic liquid functionalized gold nanoparticles synthesized using Elaeis guineensis (oil palm) kernel extract. Arabian Journal of Chemistry, 13(1), 75-85.

16. Kanchi, S., Kumar, G., Lo, A. Y., Tseng, C. M., Chen, S. K., Lin, C. Y., \& Chin, T. S. (2018). Exploitation of de-oiled jatropha waste for gold nanoparticles synthesis: a green approach. Arabian journal of chemistry, 11(2), 247-255.

17. Nadaf, N. Y., \& Kanase, S. S. (2019). Biosynthesis of gold nanoparticles by Bacillus marisflavi and its potential in catalytic dye degradation. Arabian Journal of Chemistry, 12(8), 4806-4814.

18. Salley, D., Keenan, G., Grizou, J., Sharma, A., Martín, S., \& Cronin, L. (2020). A nanomaterials discovery robot for the Darwinian evolution of shape programmable gold nanoparticles. Nature Communications, 11(1), 1-7.

19. Battie, Y., Izquierdo-Lorenzo, I., Resano-Garcia, A., Naciri, A. E., Akil, S., Adam, P. M., \& Jradi, S. (2017). Determination of gold nanoparticle shape from absorption spectroscopy and ellipsometry. Applied Surface Science, 421, 301-309

20. Samimi, S., Maghsoudnia, N., Eftekhari, R. B., \& Dorkoosh, F. (2019). Lipid-Based Nanoparticles for Drug Delivery Systems. In Characterization and Biology of Nanomaterials for Drug Delivery (pp. 47-76). Elsevier.

21. Joseph, E., \& Singhvi, G. (2019). Multifunctional nanocrystals for cancer therapy: A potential nanocarrier. In Nanomaterials for Drug Delivery and Therapy (pp. 91116). William Andrew Publishing.

22. Shnoudeh, A. J., Hamad, I., Abdo, R. W., Qadumii, L., Jaber, A. Y., Surchi, H. S., \& Alkelany, S. Z. (2019). Synthesis, Characterization, and Applications of Metal Nanoparticles. In Biomaterials and Bionanotechnology (pp. 527-612). Academic Press.

23. Wang, L., Zhang, X., Cui, Y., Guo, X., Chen, S., Sun, H., ... \& Kang, J. (2020). Polyethyleneimine-oleic acid micelle-stabilized gold nanoparticles for reduction of 4-nitrophenol with enhanced performance. Transition Metal Chemistry, 45(1), 31-39.

24. Irfan, M., Moniruzzaman, M., Ahmad, T., Mandal, P. C., Bhattacharjee, S., \& Abdullah, B. (2017). Ionic liquid based extraction of flavonoids from Elaeis guineensis leaves and their applications for gold nanoparticles synthesis. Journal of Molecular Liquids, 241, 270-278. 
25. Irfan, M., Moniruzzaman, M., Ahmad, T., Mandal, P. C., Abdullah, B., \& Bhattacharjee, S. (2020). Growth kinetic study of ionic liquid mediated synthesis of gold nanoparticles using Elaeis guineensis (oil palm) kernels extract under microwave irradiation. Arabian Journal of Chemistry, 13(1), 620-631.

26. iu, X., Atwater, M., Wang, J., \& Huo, Q. (2007). Extinction coefficient of gold nanoparticles with different sizes and different capping ligands. Colloids and Surfaces B: Biointerfaces, 58(1), 3-7.

27. Satija, Jitendra. (2014). Re: How can we calculate the concentration of nanoparticles in a solution? Retrieved from: https://www.researchgate.net/post/How-can-we-calculate-the-concentrationof-nanoparticles-in-a-solution/52fcf687d11b8bc7278b45c6/citation/download.

28. https://nanocomposix.com/pages/nanoparticle-volume-mass-andconcentration\#target

29. Field, L. D., Li, H. L., \& Magill, A. M. (2020). Organic structures from spectra. John Wiley \& Sons.

30. Mak, J. S., Rutledge, S. A., Abu-Ghazalah, R. M., Eftekhari, F., Irizar, J., Tam, N. C., \& Helmy, A. S. (2013). Recent developments in optofluidic-assisted Raman spectroscopy. Progress in Quantum Electronics, 37(1), 1-50.

31. Sen, S., \& Chakraborty, R. (Eds.). (2019). Herbal Medicine in India: Indigenous Knowledge, Practice, Innovation and its Value. Springer Nature.

32. Keshari, A. K., Srivastava, R., Singh, P., Yadav, V. B., \& Nath, G. (2020). Antioxidant and antibacterial activity of silver nanoparticles synthesized by Cestrum nocturnum. Journal of Ayurveda and integrative medicine, 11(1), 37-44.

33. Khalil, I., Yehye, W. A., Etxeberria, A. E., Alhadi, A. A., Dezfooli, S. M., Julkapli, N. B. M., ... \& Seyfoddin, A. (2020). Nanoantioxidants: Recent trends in antioxidant delivery applications. Antioxidants, 9(1), 24.

34. Lee, Y. J., Ahn, E. Y., \& Park, Y. (2019). Shape-dependent cytotoxicity and cellular uptake of gold nanoparticles synthesized using green tea extract. Nanoscale research letters, 14(1), 1-14.

35. Leonenko, N., \& Leonenko, O. (2020). Factors Influencing the Manifestation of Toxicity and Danger of Nanomaterials. Innovative Biosystems and Bioengineering, 4(2), 75-88.

36. Vairavel, M., Devaraj, E., \& Shanmugam, R. (2020). An eco-friendly synthesis of Enterococcus sp.-mediated gold nanoparticle induces cytotoxicity in human colorectal cancer cells. Environmental Science and Pollution Research, 27(8), 8166-8175.

37. Jeyarani, S., Vinita, N. M., Puja, P., Senthamilselvi, S., Devan, U., Velangani, A. J., \& Kumar, P. (2020). Biomimetic gold nanoparticles for its cytotoxicity and biocompatibility evidenced by fluorescence-based assays in cancer (MDA-MB231) and non-cancerous (HEK-293) cells. Journal of Photochemistry and Photobiology B: Biology, 202, 111715. 
38. Lee, Y. J., \& Park, Y. (2020). Green synthetic Nanoarchitectonics of gold and silver nanoparticles prepared using quercetin and their cytotoxicity and catalytic applications. Journal of nanoscience and nanotechnology, 20(5), 2781-2790.

\section{ACKNOWLEDGEMENTS}

We would like to thank LABIOM at UFES for help with UV-vis analysis and NICEnano at UFES for TEM images. This study was supported in part by FINEP, CNPq and FAPES.

\section{AUTHOR CONTRIBUTIONS}

M.C.C.G. conceived the project. L.A.C., D.M.F, L.P.C.S. and W.J.K. conducted the experiments. A.R.S. carried out the Zeta and DLS analysis. E.A.S.F. carried out the ICPMS analysis. J.P.O. prepared and performed TEM analysis. M.C.C.G. and L.A.C. wrote the manuscript. All the authors discussed the results and commented on the manuscript.

\section{COMPETING INTERESTS}

The authors declare no competing interests. 


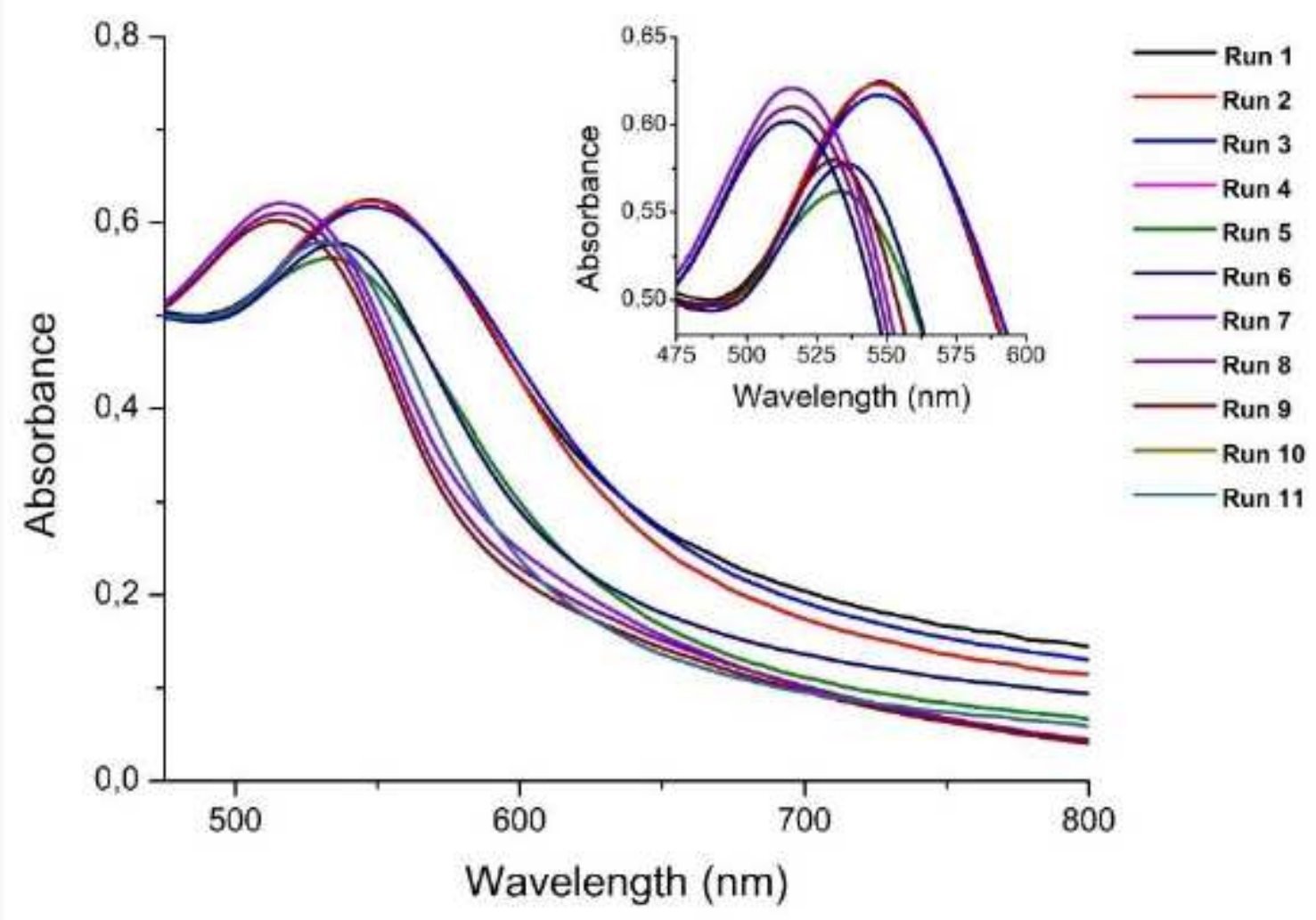

Figure 1

UV-Vis absorption of 11 samples synthesized according to full factorial design 32. Run 1 (pH 4.7, Time 1 min); Run 2 (pH 4.7, Time 6 min); Run 3 (pH 4.7, Time 11 min); Run 4 (pH 7.7, Time 1 min); Run 5 (pH 7.7, Time 6 min); Run 6 (pH 7.7, Time 11 min); Run 7 (pH 10.7, Time 1 min); Run 8 (pH 10.7, Time 6 min); Run 9 (pH 10.7, Time 11 min); Run 10 (pH 7.7, Time 6 min); Run 11 (pH 7.7, Time 6 min). 

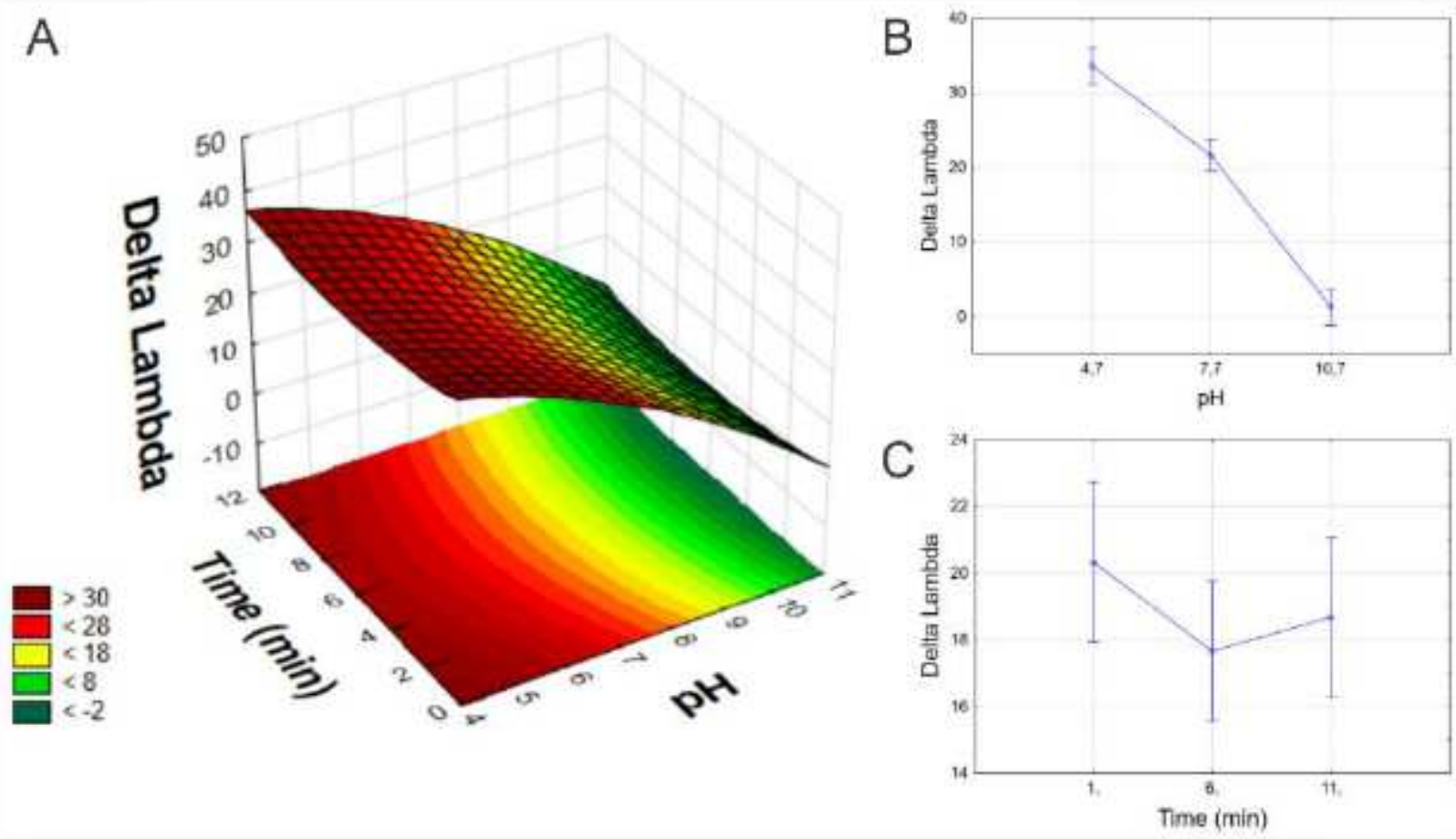

\section{Figure 2}

(A) Response surface graph by complete factorial design 32 of gold nanoparticles synthesis with $\mathrm{V}$. oleifera extract. (B) Influence of $\mathrm{pH}$ on $\Delta \lambda$ response variable. (C) Influence of Time in relation to the response variable $\Delta \lambda$. 

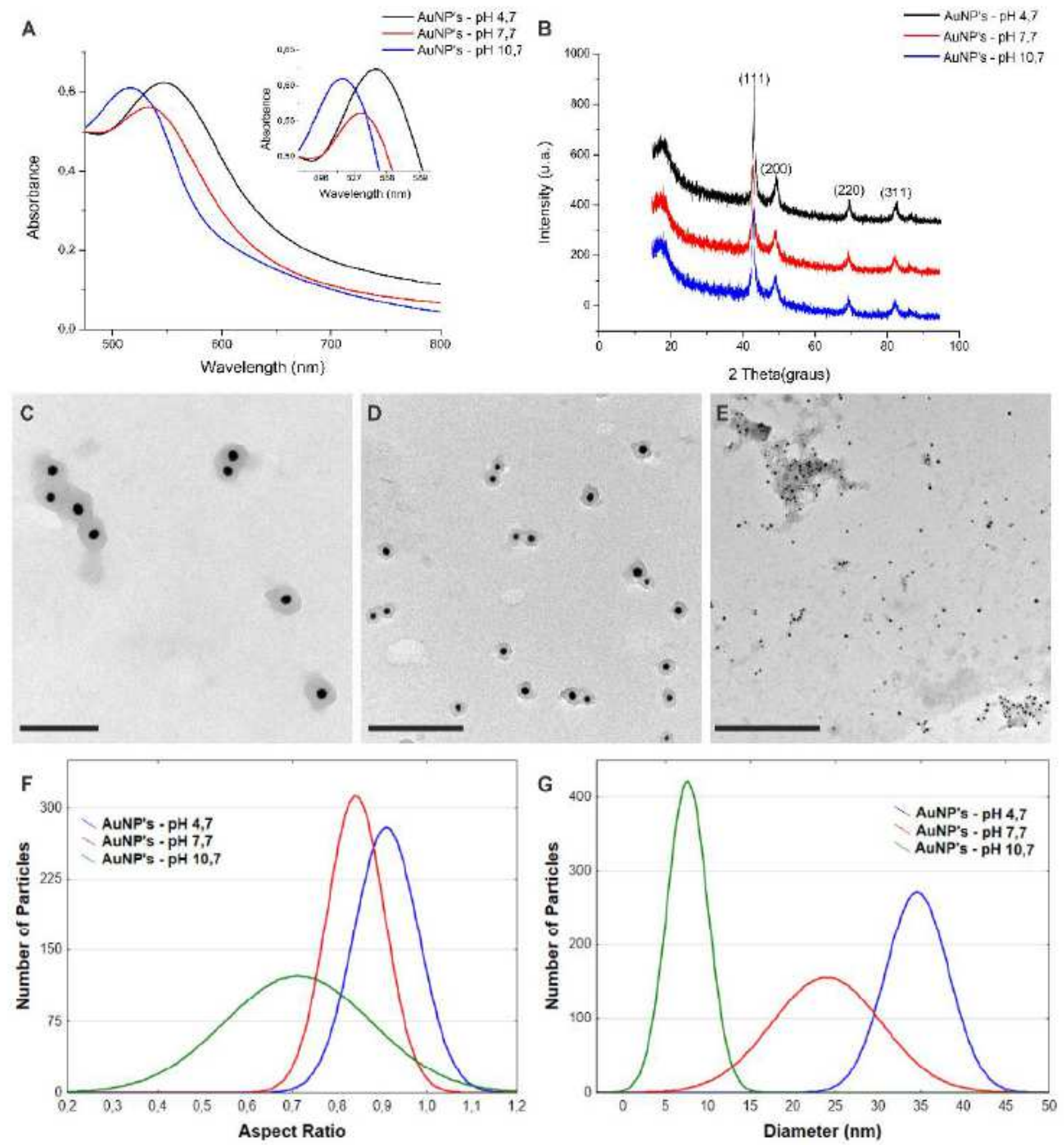

\section{Figure 3}

(A) SPR band of AuNPs synthesized using V. oleifera extract as reducing agent with different pHs. (B) Xray diffraction of AuNPs. Images obtained by transmission electron microscopy (C) AuNPs pH - 4.7, (D) AuNPs - pH 7.7, and (E) AuNPs - pH 10.7, scale bar 200 nm. (F) Aspect ratio of 1000 particles obtained from images acquired by transmission electron microscopy (TEM) and (G) Histogram showing the Gaussian distribution of diameter. 

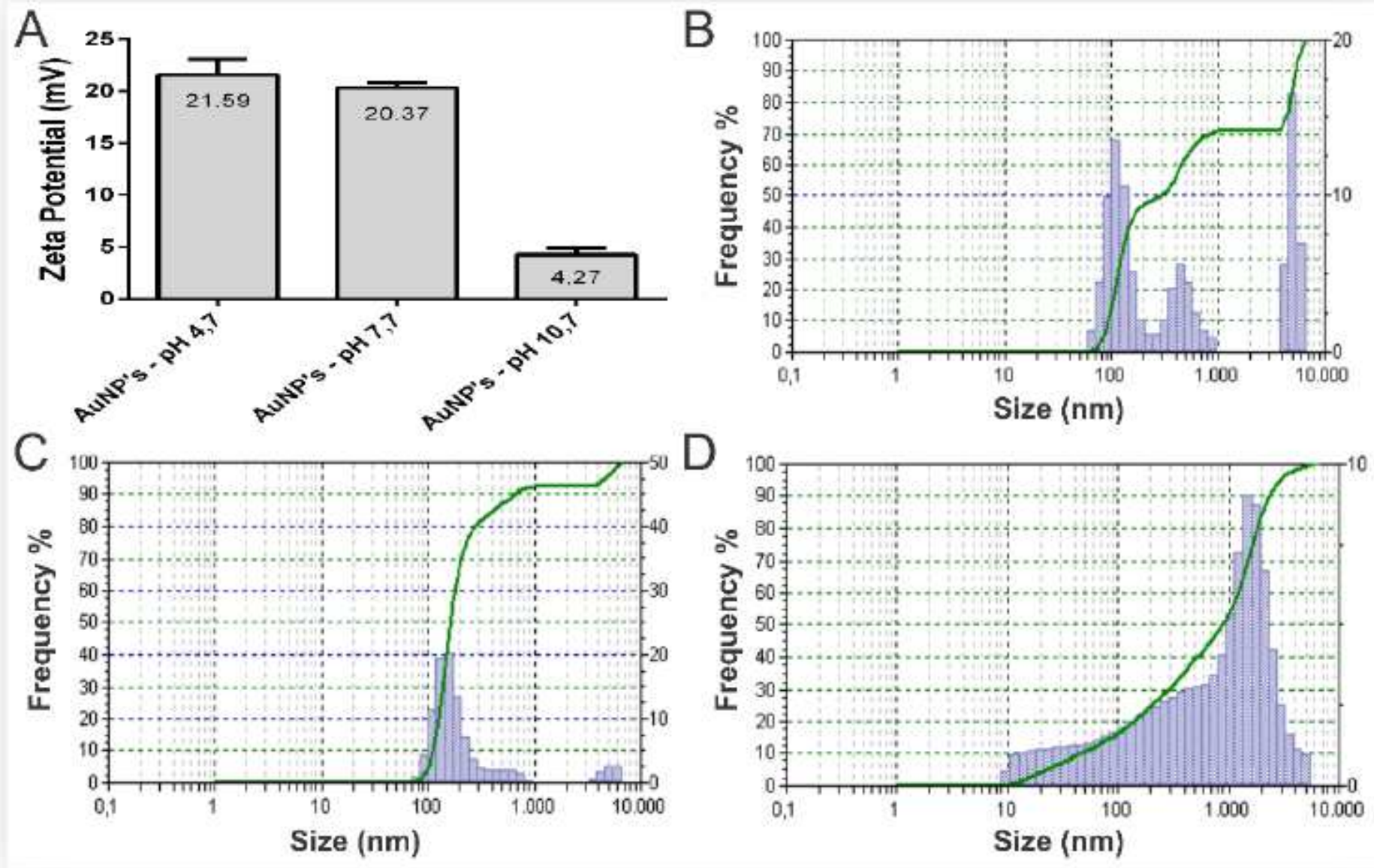

\section{Figure 4}

(A) Zeta potential of synthesized nanoparticles. (B) Nanoparticle DLS graph of AuNPs - pH 4. 7. (C) Nanoparticle DLS graph of AuNPs - pH 7.7. (D) Nanoparticle DLS graph of AuNPs - pH 10.7.
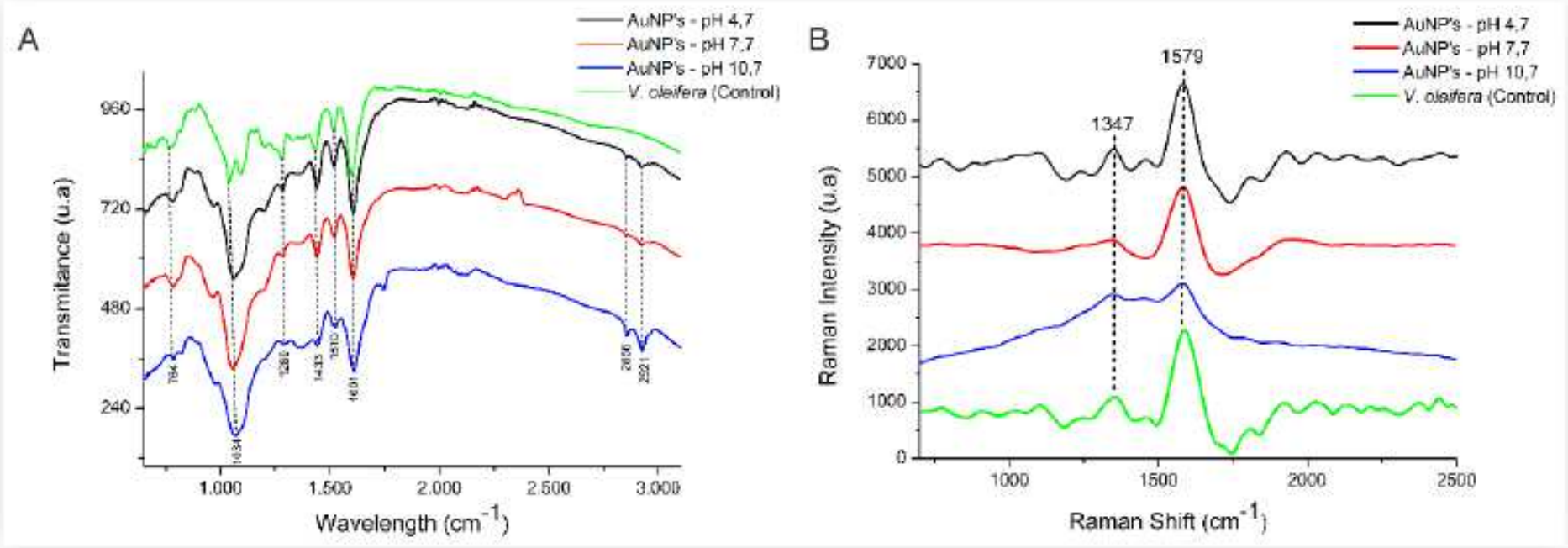

Figure 5 
(A) Raman spectra and (B) Infrared spectrum of gold nanoparticles synthesized with V. oleifera with different pHs $(4.7,7.7,10.7)$ and V. oleifera extract.

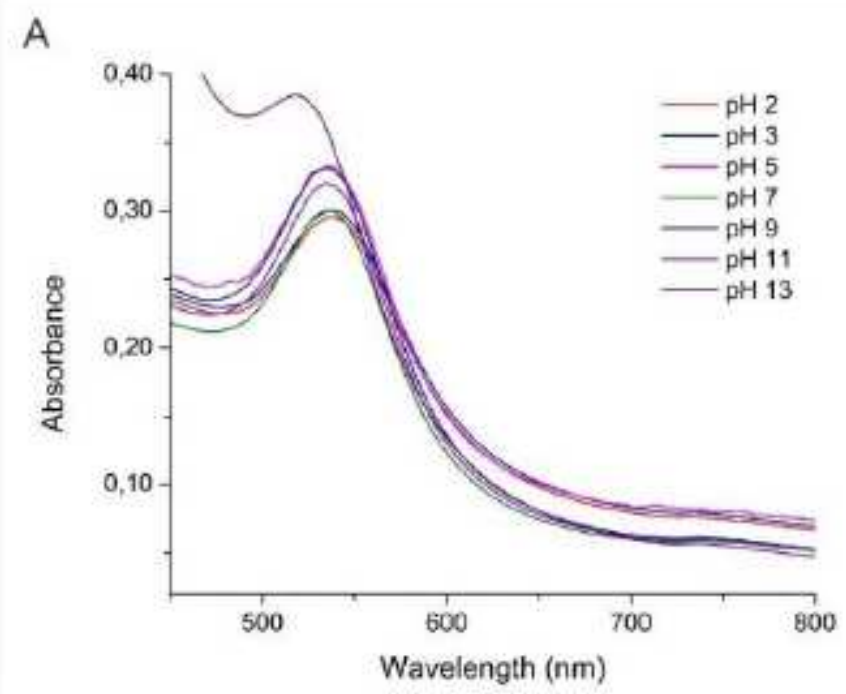

B

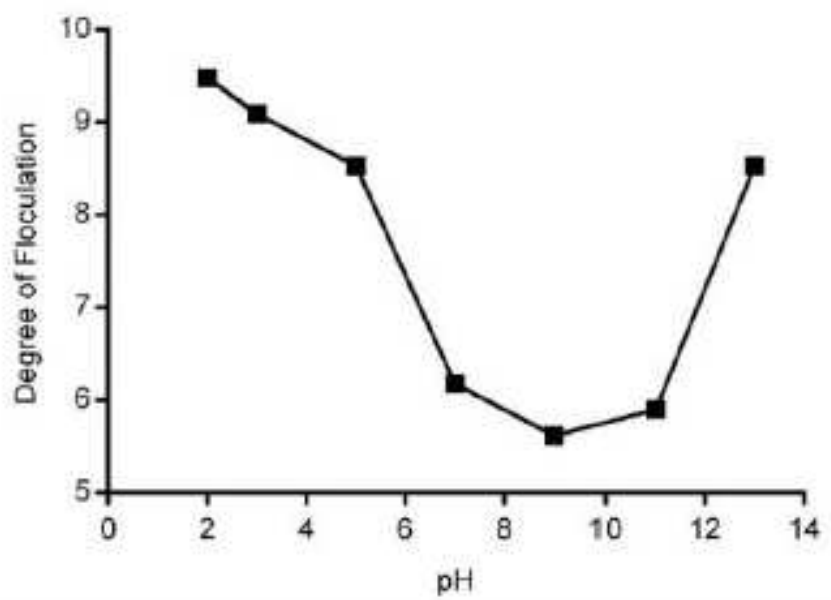

C

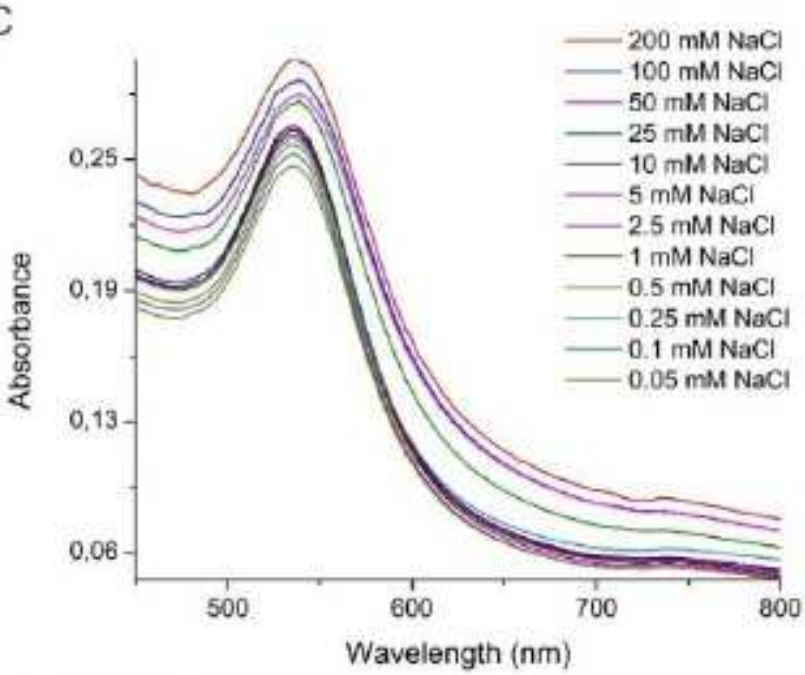

D

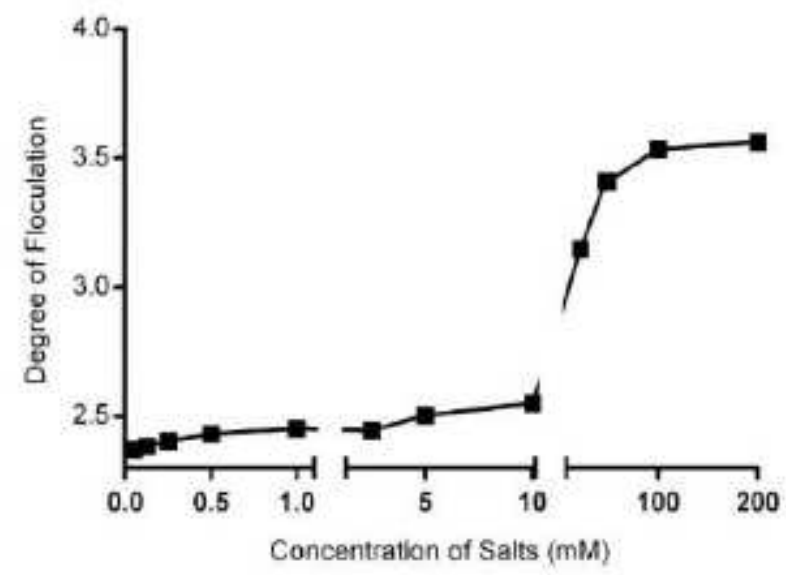

Figure 6

Absorption spectra showing the AuNPs prepared at $\mathrm{pH} 7.7$ in the presence of different salt concentrations (A) and $\mathrm{pH}$ (C). Flocculation degree based on the increase of the area between 600 and $800 \mathrm{~nm}$ in different salt concentrations (B) and $\mathrm{pH}(\mathrm{D})$. 
A ABTS+

B

DPPH
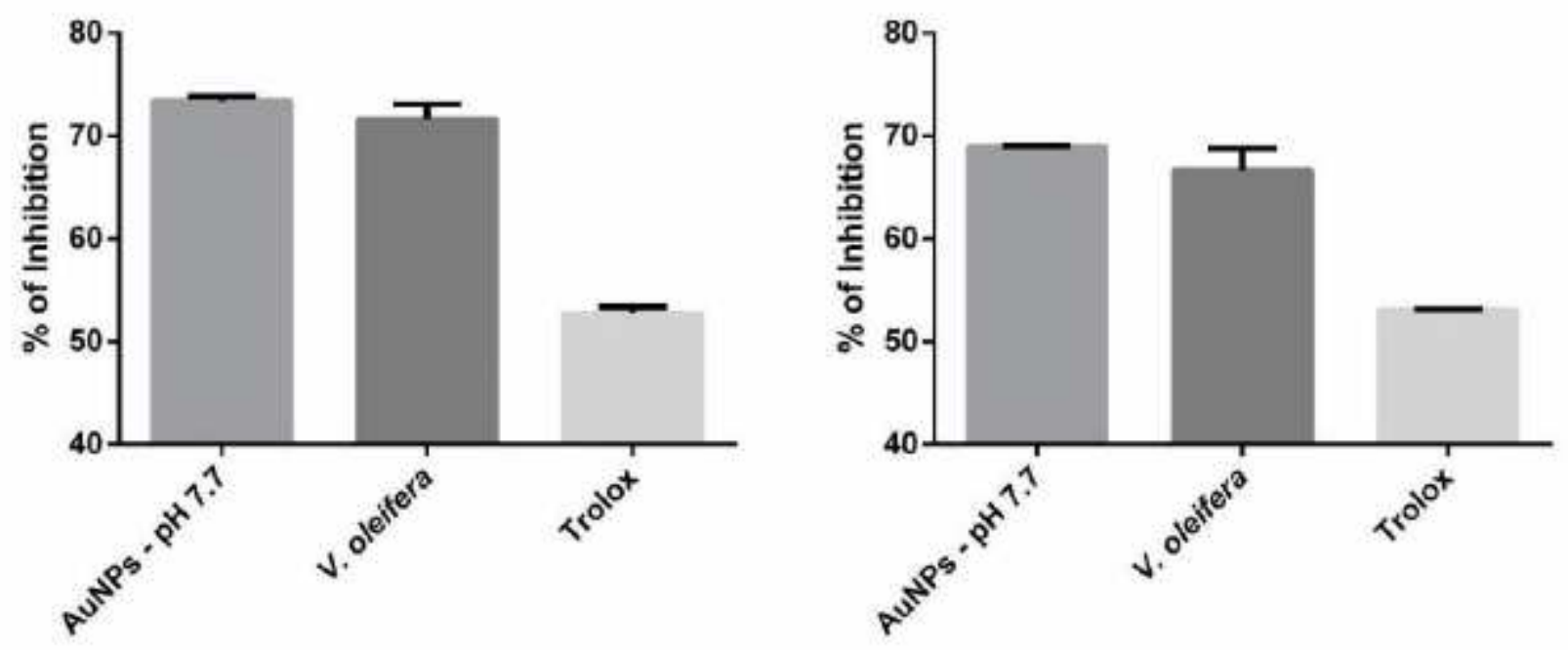

Figure 7

Comparison between the antioxidant activity of AuNPs - pH7.7, V. oleifera extract and Trolox (control) using (A) ABTS + and (B) DPPH assay.
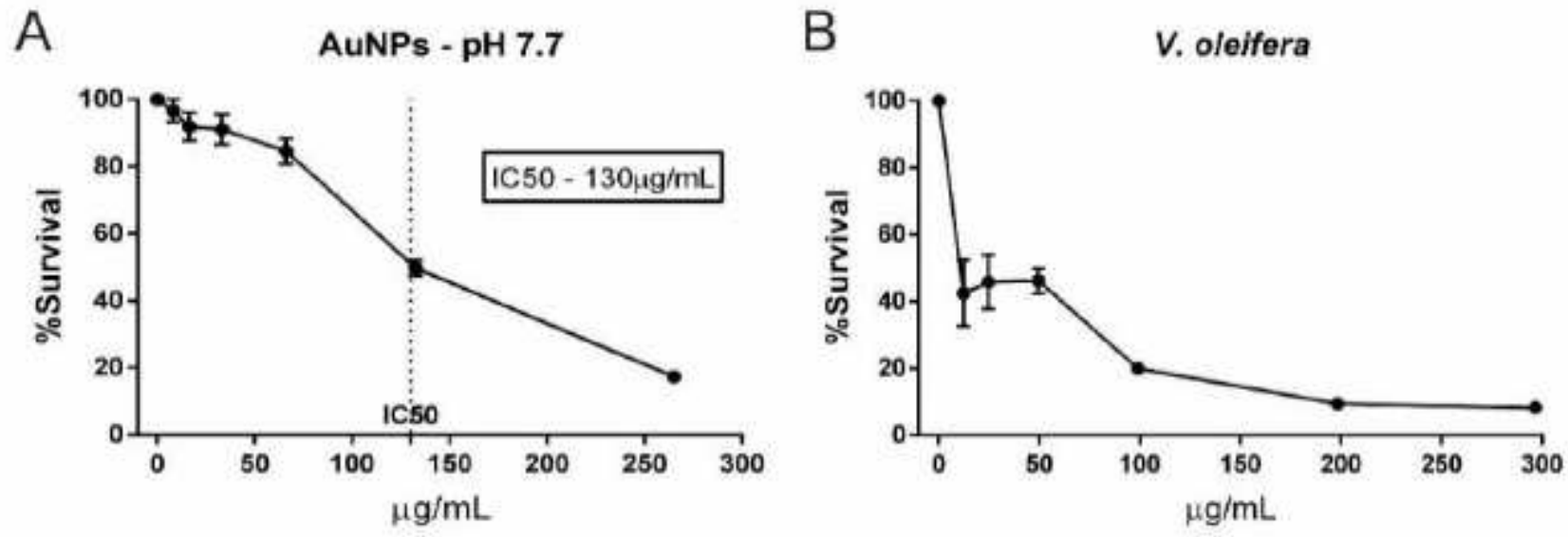

Figure 8

Survival percentage of (A) AuNPs at pH 7.7 and (B) V. oleifera extract.

\section{Supplementary Files}

This is a list of supplementary files associated with this preprint. Click to download.

- SupportingInformation.pdf 